\title{
MANIFIESTO POR UNA PEDAGOGÍA POST-CRÍTICA (TRADUCCIÓN AL ESPAÑOL) ${ }^{1}$
}

\section{Manifesto for a post-critical pedagogy (Spanish translation)}

\author{
Naomi HODGSON*, Joris VLIEGHE** y Piotr ZAMOJSKI**** \\ *Liverpool Hope University. Reino Unido. \\ bodgson@bope.ac.uk \\ bttps://orcid.org/0000-0002-0171-4748 \\ ** Katholieke Universiteit Leuven. Bélgica. \\ joris.vlieghe@kuleuven.be \\ bttps://orcid.org/0000-0001-6307-3221 \\ **** University of Gdańsk. Polonia. \\ piotr.zamojski@ug.edu.pl \\ https://orcid.org/0000-0002-5505-7579
}

Fecha de publicación en línea: 01/07/2020

RESUMEN

A finales de 2016 se presentó en la Liverpool Hope University el conocido Manifesto for Post-Critical Pedagogy elaborado por los profesores Naomi Hodgson, Joris Vlieghe y Piotr Zamojski. Posteriormente se publicó en 2017 con respuestas de Tyson Lewis, Geert Thyssen, Olga Ververi, Oren Ergas, Norm Friesen y Stefan Ramaekers, a las que se añadieron otras tantas contestaciones de los autores. Los cinco principios propuestos en el Manifiesto son: 1) Hay principios que defender. 2) De la pedagogía hermenéutica a una hermenéutica pedagógica. 3) De una pedagogía crítica a una pedagogía post-crítica. 4) Del optimismo cruel a la esperanza en el presente. 5) Desde una educación para la ciudadanía a un amor por el mundo. La revista Teoría de la Educación. Revista Interuniversitaria, en su voluntad de ofrecer a la comunidad

1. Manifesto for a Post-critical Pedagogy (pp. 15-19). London: Punctum Books, 2017. Recuperado de: https://punctumbooks.com/titles/manifesto-for-a-post-critical-pedagogy/ Traducción: Bianca Thoilliez. 
académica una visión plural de las nuevas tendencias en los análisis teóricos de la educación, propone en este número monográfico la traducción al español del Manifiesto, una introducción de los autores en el que dan cuenta de las razones y desarrollos del Manifiesto y, por último, una serie de respuestas que han elaborado miembros destacados de la comunidad académica iberoamericana del campo de la Teoría de la Educación.

Palabras clave: pedagogía crítica; pedagogía post-crítica; manifiesto.

\section{ABSTRACT}

In late 2016, the well-known Manifesto for Post-Critical Pedagogy written by Naomi Hodgson, Joris Vlieghe and Piotr Zamojski was presented at Liverpool Hope University. It was subsequently published in 2017 with responses from Tyson Lewis, Geert Thyssen, Olga Ververi, Oren Ergas, Norm Friesen, and Stefan Ramaekers, to which many other responses from the authors were added. The five principles proposed in the Manifesto are: 1) There are principles to defend. 2) From hermeneutical pedagogy to a pedagogical bermeneutic. 3) From critical to a post-critical pedagogy. 4) From cruel optimism to bope in the present. 5) From education for citizenship to love for the world. Following its mission of bringing into the academic community a pluralistic panorama on the new theoretical analyses of education, the journal Teoría de la Educación. Revista Interuniversitaria presents the Spanish translation of the Manifesto, an introduction by its authors in which they offer an account on the reasons and latest developments of the Manifesto and, finally, a series of responses by prominent members of the Ibero-American academic community in the field of Educational Theory.

Key words: critical pedagogy; post-critical pedagogy; manifesto.

Cuando se formulan principios, al menos en filosofía de la educación, parece que se esté volviendo a formas de análisis normativo y conceptual propios de estilos filosóficos anglófonos y analíticos. Sin embargo, la filosofía postestructuralista y postmoderna - al menos tal y como han sido retomadas en la teoría de la educación y en el pensamiento popular en general-, a menudo, traen consigo un cierto relativismo, el cual, al mismo tiempo que hoy resulta potencialmente inclusivo e, indudablemente, es constitutivo de la posibilidad de la elección individual, hace que defender principios sea más difícil. Al enunciar principios en la forma de un manifiesto, nos arriesgamos a ser acusados de universalismo, de normatividad excluyente. Pero quizá haya llegado el momento de cuestionar la asunción de que estas características sean siempre inherentemente negativas. A continuación, proponemos una serie de principios fundados en la creencia de la posibilidad de transformación, tal y como se establece en la teoría y la pedagogía críticas, pero con una actitud afirmativa: una orientación post-crítica hacia la educación que se beneficia de las condiciones actuales y que se funda en la esperanza de lo que aún está por venir. 
El primer principio que aquí se establece es, simplemente, que hay principios que defender. Lo cual, en sí mismo, no nos compromete con nada más allá, es decir, no nos compromete a tener que hacer " $\mathrm{X}$ ". No se trata de afirmar la normatividad en el sentido de definir un estado ideal, presente o futuro, contra el cual debiera juzgarse la práctica actual. Por lo tanto, este principio podría caracterizarse como la defensa de un giro que nos lleve desde una normatividad de procedimientos

\section{hacia una normatividad de principios.}

En la teoría de la educación, el pensamiento postestructuralista y postmoderno a menudo se han entendido en términos de políticas de identidad, a lo cual ha seguido una preocupación por la otredad, la alteridad y la voz. El respeto al otro y a la diferencia requieren que el educador acepte que nunca podemos conocer completamente al otro. Cualquier intento de hacerlo constituye, por así decirlo, una forma de "violencia» hacia el otro. De ahí que las posibilidades de actuar y de hablar estén suspendidas; un problema tanto político como educativo, quizá bien resumido en la expresión que a menudo escuchamos (aunque entre susurros) de «Sé que esto ya no se puede decir, pero..., y en los lamentos de la llamada corrección política. Aceptar que nunca podemos entender por completo al otro - individuos o culturas - no debería implicar que no podamos hablar. Esta muestra de "respeto" olvida que entender y respetar son desafíos y esperanzas eternos. Aquí partimos de la asunción de que podemos hablar y actuar - juntos- y, por lo tanto, pasar de la pedagogía hermenéutica que conlleva la pedagogía crítica, a defender una -segundo principio- hermenéutica pedagógica. Son los desafíos que representa vivir juntos en un mundo común los que constituyen la esperanza que hace que la educación siga pareciendo una actividad que merece la pena. La hermenéutica no como un problema (irresoluble), sino como algo que el educador necesita crear. No deberíamos hablar y actuar basándonos en asunciones apriorísticas acerca de la (im)posibilidad de una verdadera comprensión y respeto mutuos, sino, más bien, mostrar que, a pesar de las muchas diferencias que nos dividen, hay espacio para lo común que solo surge a posteriori (véanse Arendt, Badiou, Cavell).

En buena parte de la investigación, la política y la práctica educativas, a menudo, se ignora la existencia de un espacio de lo común para concentrarse en la (in)justicia y la exclusión sociales, basadas en la asunción de desigualdad. El ethos de la pedagogía crítica aguanta hoy sobre el compromiso de alcanzar la igualdad, no a través de la emancipación sino, más bien, a través del empoderamiento de los individuos y las comunidades. Sin embargo, termina siendo un ethos desesperanzado - por no decir cínico-, como resultado de lo aparentemente ineludible que resulta ser la racionalidad neoliberal. Pero, el orden dado de las cosas no responde a un principio de necesidad y, por lo tanto, por insuperable que parezca ese orden actual de las cosas, hay esperanza. El tercer principio se basa, pues, en asumir que la igualdad (véase Rancière) y la posibilidad de transformación —a 
nivel individual y colectivo- conllevan un giro desde una pedagogía crítica a

\section{una pedagogía post-crítica.}

Esta no es en ningún caso una posición anti-crítica. Gracias al enorme y extremadamente poderoso aparato crítico que se desarrolló a lo largo del siglo XX, somos conscientes de las principales características del statu quo en el que estamos inmersos. Pero, a diferencia de la crítica inherente a las instituciones sociales que ha estado centrada en su disfuncionalidad, o de la crítica utópica que ha partido de posiciones trascendentes conducentes al eterno aplazamiento del cambio deseado, creemos que ha llegado el momento de centrar nuestros esfuerzos en intentar reclamar las partes de nuestra experiencia que han sido reprimidas; vemos la tarea de la pedagogía post-crítica no como un esfuerzo por desenmascarar sino por proteger y por cuidar (véanse Latour, Haraway). Este cuidado y protección nos llevan a preguntarnos de nuevo por lo que son la educación, la crianza, la escuela, el estudio, el pensamiento y la práctica. Esta recuperación implica dejar de establecer una relación crítica — tratando de desvelar lo que realmente está sucediendo- o una relación instrumental —mostrando a los educadores qué deben hacer-, para crear un espacio de pensamiento que permita que la práctica tenga lugar de nuevo. Esto significa (re)establecer nuestra relación con las palabras, abriéndolas a cuestionamientos, y prestar atención filosófica a aquellos aspectos devaluados de nuestras formas de vida, y, de ahí — de acuerdo con una normatividad de principios- defender estos acontecimientos como autotélicos y no funcionalistas, simplemente porque merecen la pena ser cuidados.

La educación se basa, en un sentido muy práctico, en la esperanza. Sin embargo, en la pedagogía crítica "tradicional» esta esperanza de emancipación se ha basado en el mismo régimen de desigualdades que pretendía superar, reflejándose en tres formas particulares:

1) Promueve un tipo de pedagogía hermenéutica: el educador asume que al otro le faltan los medios para entender que está encadenado como consecuencia de la forma que ese otro tiene de ver el mundo. El educador se sitúa fuera de esa condición, teniendo que criticar el presente y liberar a los no iluminados (véase la caverna de Platón).

2) Lo cual se reduce, en realidad, a reafirmar la posición superior de uno y, por lo tanto, a reinstalar un régimen de desigualdad. No se produce una verdadera ruptura con el statu quo.

3) Además, el punto de vista externo desde el que habla el pedagogo crítico se encuentra una y otra vez encadenado al statu quo, pero en un mero sentido negativo: la crítica está animada por la pasión del odio. Al hacer esto, el pedagogo crítico se adhiere subrepticiamente a lo que es y a lo que siempre será. Los enfoques críticos y dialécticos dan cuenta de esta actitud negativa. 
Por lo tanto, el pedagogo asume el papel de quien tiene que retirar el velo; sin embargo, la posición desde la cual retira el velo no es distinta del statu quo sobre el cual mantiene un juicio externo. Ofrecemos la idea de una pedagogía post-crítica, que exige un amor por el mundo, para formular de un modo más positivo el papel del pedagogo como aquel que inicia a la nueva generación en el mundo común. Esto no quiere decir que se acepten las cosas tal y como son, sino que se afirma el valor de lo que hacemos en el presente y, por lo tanto, de las cosas que valoramos que merecen ser legadas. Pero no tal y como son: la esperanza educativa tiene que ver con la posibilidad de renovar nuestro mundo común. Cuando amamos verdaderamente el mundo, nuestro mundo, debemos estar dispuestos a legarlo a la nueva generación, bajo la asunción de que ellos — los recién llegados- puedan retomarlo, en sus propios términos. De ahí que, el cuarto principio implique un giro desde el optimismo cruel (véase Berlant) a la esperanza en el presente. El cinismo y el pesimismo no son un reconocimiento de cómo son las cosas, sino su evitación (véanse Cavell, Emerson).

En sus formulaciones actuales, cuidar del mundo se presenta bajo la forma de una educación para la ciudadanía, educación para la justicia social, educación para la sostenibilidad, etc., dentro de una noción particular de ciudadanía global y de una forma emprendedora de diálogo intercultural. Aunque en ocasiones se apuntale sobre una pedagogía crítica y progresista, en tales formulaciones la preocupación por la responsabilidad por el mundo se presenta con finalidades externas a la educación. Por muy tradicional o conservador que todo esto pueda sonar, deseamos defender la educación por el bien de la educación misma: la educación como el estudio de y la iniciación en una materia por su valor intrínseco y educativo, más que instrumental, de manera que pueda ser retomada de nuevo por la nueva generación. Actualmente, el mundo (futuro) ya se presenta como apropiado por la «educación para..." y se vuelve instrumental para (nuestros) otros fines. Así, el quinto principio nos lleva desde una educación para la ciudadanía a un amor por el mundo. Ha llegado el momento de reconocer y afirmar que hay cosas buenas en el mundo que merecen ser preservadas. Ha llegado el momento de que al desenmascaramiento del mundo le siga un reconocimiento esperanzado del mundo. Ha llegado el momento de situar lo que de bueno hay en el mundo - aquello que se encuentra amenazado y que deseamos preservar- en el centro de nuestra atención y de abrir un espacio conceptual en el que podamos aceptar nuestra responsabilidad sobre todo ello, frente a y a pesar de la opresión y la melancolía silenciosa. 